\title{
Numerical modelling of flow around thermally loaded object
}

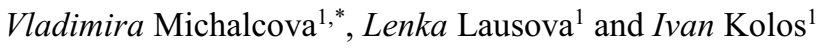 \\ ${ }^{1}$ VŠB - Technical University of Ostrava, Faculty of Civil Engineering, 70833 Ostrava-Poruba, \\ Czech Republic
}

\begin{abstract}
The paper focuses on numerical analysis of selected turbulent characteristics near flow around thermally loaded object. Changes in the flow and thermal fields are examined in response to the change of the reference values of velocity and temperature of the flow around body. The results are evaluated at different heights on the windward side, above the object and on the leeward side. The tasks are solved using computational fluid dynamics (CFD) software based on the finite volume method.
\end{abstract}

\section{Introduction}

The task of the flow around heated model of a hill is numerically modelled in cooperation with the department of experimental research CWT CET in Telč $[1,2]$. The reason is the "mapping" of the vertical heat flux which affects the velocity profiles of the flow field of wind $[3,4]$. The tasks are solved using CFD codes in software Ansys Fluent. From the viewpoint of numerical modelling this is an interesting issue in terms of flow characteristics [5]. The model of the solved hill has a height $h=200 \mathrm{~mm}$ (Fig. 1 on the left). There are considered two cases of the reference air velocity: $v_{0}=0.5 \mathrm{~m} / \mathrm{s}$ a $v_{0}=1.5 \mathrm{~m} / \mathrm{s}$.

The described process corresponds to a flow of Reynolds number $R e=6 \cdot 10^{3}-2 \cdot 10^{4}$. It is a flowing with the transition from the low turbulence at the beginning to the fully developed turbulence behind the obstacle [6-8]. A flow around and temperature loaded object contributes to a change of momentum and turbulent flow characteristics [9] that leads to a significant change in the momentum in the transition area of turbulent flow at low Re numbers.

The experimental measurements for both air velocities $v_{0}[10]$ were carried out for the temperature of the hill $T=150{ }^{\circ} \mathrm{C}$. The results were evaluated from the wind tunnel and numerical simulations for above mentioned cases in [10], there have been achieved satisfactory conclusions. In the submitted paper the task is expanded by a numerical calculation for cases where the model temperature of flow around hill is reaching values $T=100{ }^{\circ} \mathrm{C}$ a $T=200{ }^{\circ} \mathrm{C}$. The velocity profiles are monitored at four height levels (Fig. 1 right), with the lowest of these $(h=0.15 \mathrm{~m})$ intersects the model of the hill in the upper quarter of the height.

The analysis of the correctness for solution of numerical models suitable for described task was carried out in [11]. Based on the comparison of outputs of the numerical

\footnotetext{
*Corresponding author: vladimira.michalcova@vsb.cz
} 
calculations and experimental measurements the best results were achieved using the Transition SST (Shear Stress Transport) model. This model was able to take into account the difference between high and low turbulence at the interface between the wake behind an obstacle and the free stream.

\section{Numerical model and computational area}

The standard $k$ - $\omega$ model is an empiric model based on the solution of two transport equations for kinetic energy $k(1)$ and dissipation of this energy $\omega(2)$ :

$$
\begin{gathered}
\frac{\partial(\rho k)}{\partial t}+\frac{\partial\left(\rho k u_{i}\right)}{\partial x_{i}}=\frac{\partial}{\partial x_{j}}\left(\Gamma_{k} \frac{\partial k}{\partial x_{j}}\right)+G_{k}-Y_{k}+S_{k} \\
\frac{\partial(\rho \omega)}{\partial t}+\frac{\partial\left(\rho \omega u_{i}\right)}{\partial x_{i}}=\frac{\partial}{\partial x_{j}}\left(\Gamma_{\omega} \frac{\partial \omega}{\partial x_{j}}\right)+G_{\omega}-Y_{\omega}+D_{\omega}+S_{\omega}
\end{gathered}
$$

where $k$ is kinetic energy $\left[\mathrm{m}^{2} / \mathrm{s}^{2}\right], \omega$ is specific dissipation rate $[1 / \mathrm{s}], G_{k}$ is generation of turbulence kinetic energy due to mean velocity gradients $\left[\mathrm{m}^{4}\right], G_{\omega}$ is generation of $\omega$ $\left[\mathrm{kg} /\left(\mathrm{m}^{3} \cdot \mathrm{s}^{2}\right)\right], \Gamma_{k}, \Gamma_{\omega}$ are effective diffusivity of $k$ and $Y_{k}, Y_{\omega}$ are dissipation of $k$ and $\omega$ due to turbulence $\left[\mathrm{kg} /\left(\mathrm{m} \cdot \mathrm{s}^{3}\right)\right],\left[\mathrm{kg} /\left(\mathrm{m}^{3} \cdot \mathrm{s}^{2}\right)\right], S_{k}, S_{\omega}$ are user-defined source terms and $D_{\omega}$ is crossdiffusion term $\left[\mathrm{kg} /\left(\mathrm{m}^{3} \cdot \mathrm{s}^{2}\right)\right]$.

Both equations describe the anticipated sheer flows well. The Transition SST model, in addition to the original $k$ and $\omega$ equations, uses two transport equations: the transport equation for the intermittency $\gamma$ (3) and the transport equation for the transition momentum thickness Reynolds number $\operatorname{Re}_{\Theta t}(4)$. By this, the model is able to take into account the difference between high and low turbulence at the interface between the wake behind the barrier and free flow:

$$
\begin{gathered}
\frac{\partial(\rho \gamma)}{\partial t}+\frac{\partial\left(\rho u_{j} \gamma\right)}{\partial x_{j}}=P_{\gamma 1}-E_{\gamma 1}+P_{\gamma 2}-E_{\gamma 2}+\frac{\partial}{\partial x_{j}}\left[\left(\mu+\frac{\mu_{t}}{\sigma_{\gamma}}\right) \frac{\partial \gamma}{\partial x_{j}}\right] \\
\frac{\partial\left(\rho \bar{e}_{\Theta t}\right)}{\partial t}+\frac{\partial\left(\rho u_{j} \overline{R e}_{\Theta t}\right)}{\partial x_{j}}=P_{\Theta t}+\frac{\partial}{\partial x_{j}}\left[\sigma_{\Theta t}\left(\mu+\mu_{t}\right) \frac{\partial \overline{R e}_{\Theta t}}{\partial x_{j}}\right]
\end{gathered}
$$

where $\mu$ is dynamic viscosity $[\mathrm{kg} /(\mathrm{m} \cdot \mathrm{s})], \mu_{t}$ is turbulent dynamic viscosity $[\mathrm{kg} /(\mathrm{m} \cdot \mathrm{s})]$, $P_{\gamma 1}, E_{\gamma 1}$ are transition sources, which include: strain rate magnitude and empirical correlation that controls the length of the transition region, $P_{\gamma 2}, E_{\gamma 2}$ are sources for the destruction/relaminarization, which include: vorticity magnitude, a critical Re number and also necessary empirical correlation and $P_{\Theta_{t}}$ is cross-diffusion term $\left[\mathrm{kg} /\left(\mathrm{m}^{3} \cdot \mathrm{s}^{2}\right)\right]$.

Near the surface of the thermally burdened and flow around object the buoyancy forces play an important role. The Boussinesq model, which describes the transfer of heat by natural convection and buoyancy, is included into the heat transfer equation. This model adds a source term describing the change in current density into the momentum equation. In such a case, it can be written the following formula for the real density of media:

$$
\left(\rho-\rho_{0}\right) \cdot g \approx \rho_{0} \cdot \beta \cdot\left(T-T_{0}\right) \cdot g
$$


where $\rho_{0}$ is the constant flow density $\left[\mathrm{kg} / \mathrm{m}^{3}\right], g$ is gravitational acceleration $\left[\mathrm{m} / \mathrm{s}^{2}\right], \beta$ is the thermal expansion coefficient $[1 / \mathrm{K}], T_{0}$ is the operating temperature $[\mathrm{K}]$ and $T$ is current temperature $[\mathrm{K}]$.

Equation (5) is solved by Boussinesq approximation:

$$
\rho=\rho_{0} \cdot(1-\beta \cdot \Delta T)
$$

If real density changes are small, as it is in the described task, the approximate solution can be considered accurate.

The task is solved in a $3 \mathrm{D}$ computational area with the following dimensions $\mathrm{b} \times \mathrm{h} \times 1=0.1 \times 1.8 \times 8 \mathrm{~m}$. The axis of the hill is located at a distance of 2 meters from the input to the area. The remaining 6 meters behind the axis is sufficiently long for the possibility of generating eddies in the wake. Boundary condition (BC) on the input is the velocity inlet, turbulence intensity is $1 \%$. BC on the output is the pressure outlet and on the side walls it is the symmetry. The height of the computational area corresponds to the wind tunnel space, so the top and bottom surfaces provides $\mathrm{BC}$ wall describing the limited space of the wind tunnel.
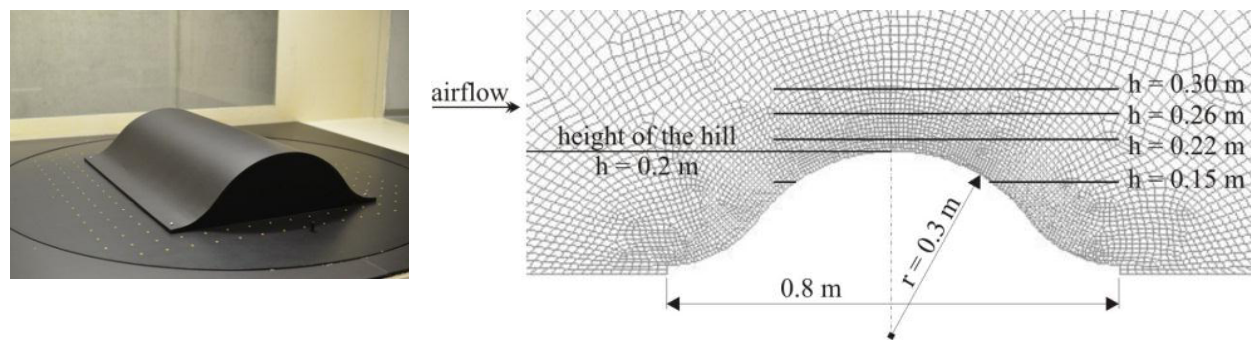

Fig. 1. Model of the hill in the wind tunnel (left) and scheme of the hill in the computational area marked with monitored height levels (right).

\section{Results}

Changes of velocity profiles for both reference velocities at given height levels are evident from Fig. 2. They are expressed as dimensionless ratios of the mean value of velocity in the direction of flow $v_{x}$ to the velocity inlet (reference) $v_{0}$. The temperature change $\pm 50{ }^{\circ} \mathrm{C}$ does not significantly affect the velocity field, which can be seen in Figure 2 . There is a distinct swirl on the leeward side (negative $v_{x}$ ) in the level of $h=0.15 \mathrm{~m}$. Gradient decreases with increasing height velocity. A slight swirl can be seen at a height of 0.2 meters above the hill $(h=0.22 \mathrm{~m})$.

Figure 3 describes the change of the temperature field in the surroundings expressed by dimensionless ratio of $T / T_{0}$, where $T$ is the mean value of temperature at a given point and $T_{0}$ is the inlet temperature of air flow $T_{0}=20^{\circ} \mathrm{C}$. The fact that the temperature gradient decreases with increasing height and simultaneously moves in the direction of air flow is confirmed in all three cases of temperature load of the model of the hill $\left(100{ }^{\circ} \mathrm{C}, 150{ }^{\circ} \mathrm{C}\right.$, $200{ }^{\circ} \mathrm{C}$ ). The gradient is lower at a higher velocity, and its shift slightly increases. This is also illustrated by isolines of temperature field for the two inlet velocities of the flow around model of the hill at temperature $T=150{ }^{\circ} \mathrm{C}$ (Fig. 4). 

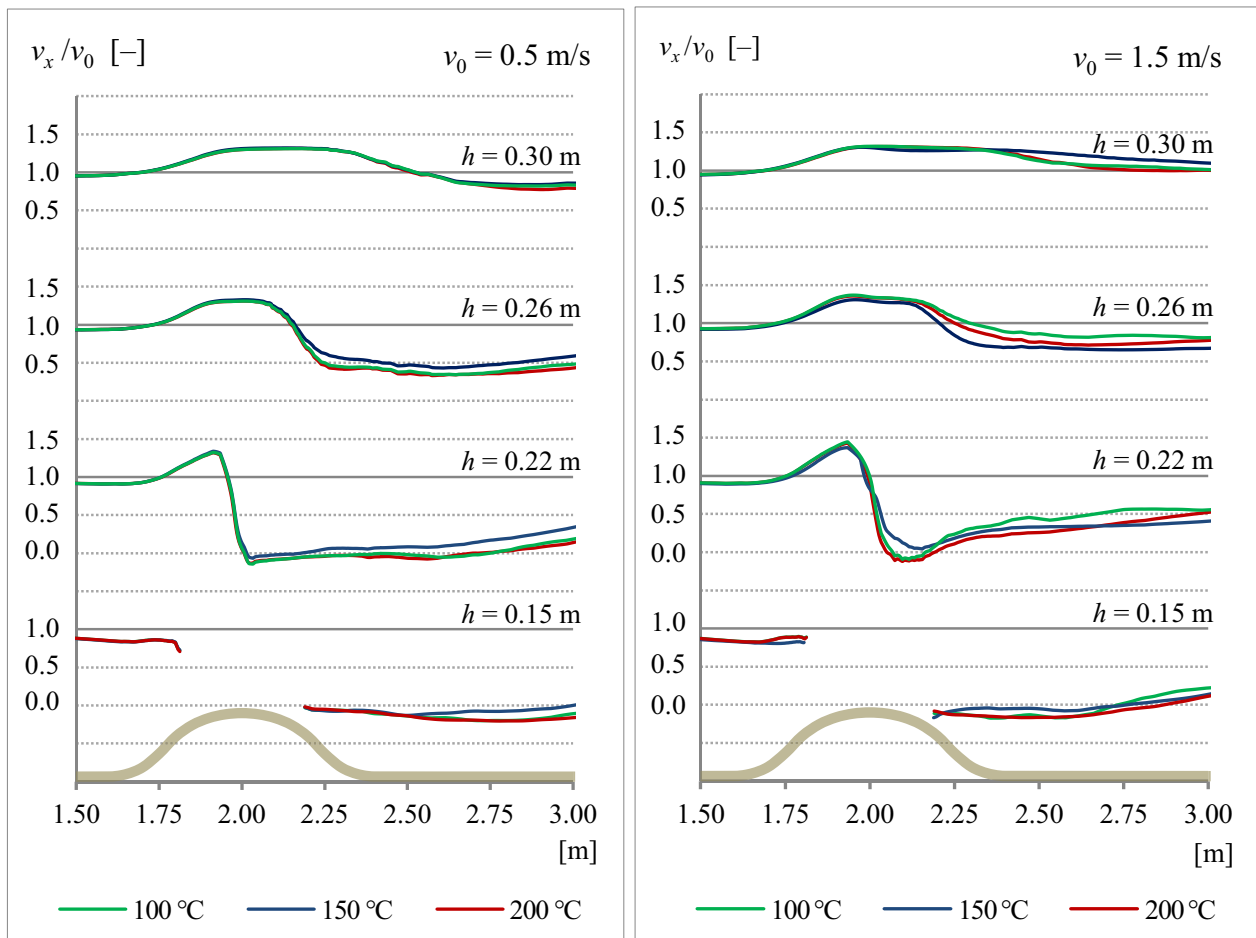

Fig. 2. Velocity field near the hill.
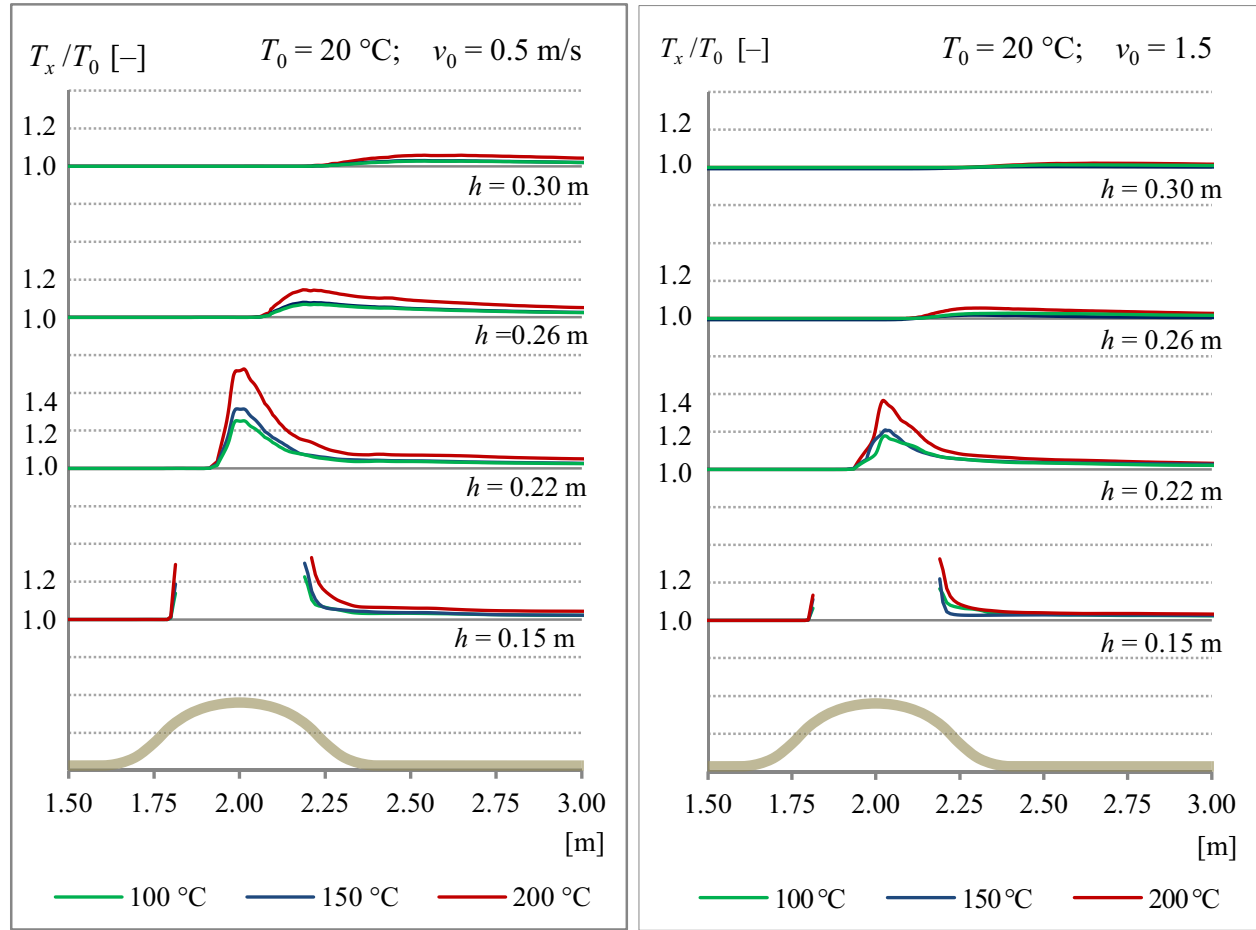

Fig. 3. Temperature field near the hill. 

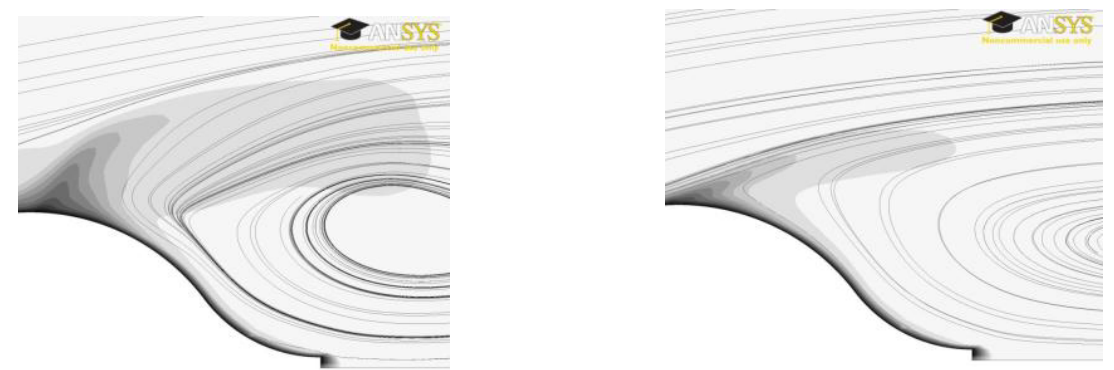

Fig. 4. Velocity isolines with thermal field for $v_{0}=0.5 \mathrm{~m} / \mathrm{s}$ (left) and $v_{0}=1.5 \mathrm{~m} / \mathrm{s}$ (right).

\section{Conclusions}

The paper presents the changes of the flow field around a thermally loaded object. The velocity and temperature fields are evaluated for the cases of temperature load changes of that object. The problem is solved numerically and builds on a task validated with experimental measurements. Those findings are presented in this work to verify correctness of that solution. It is possible to say that the results of the flow field in the case of temperature load change are satisfying. The following works of the authors will focus on a verification of new experimental measurements for detailed confirmation.

The paper has been supported by the project of "Conceptual development of science and research activities 2017" on the Faculty of Civil Engineering, VŠB-TU Ostrava.

\section{References}

1. V. Michalcova, S. Kuznetsov, J. Brozovsky, S. Pospisil, Appl. Mech. Mater. 617, 275 (2014)

2. V. Michalcova, S. Kuznetsov, S. Pospisil, Math. Comput. Simulat. 8, 135 (2014)

3. Y. Qu, M. Milliez, L. Musson-Genon, B. Carissimo, J. Wind. Eng. Ind. Aerod. 104106, 474 (2012)

4. S.S. Pillai, R. Yoshie, J. Wind. Eng. Ind. Aerod. 104-106, 447 (2012)

5. J. Kralik, O. Hubova, L. Konecna, Transactions of the V $\breve{S} B$ - Technical University of Ostrava, Civil Engineering Series, 15, (2016)

6. J.E. Pieterse, T.M. Harms, J. Wind. Eng. Ind. Aerod. 121, 82 (2013)

7. H. Nakayama, T. Takemi, H. Nagai, Adv. Sci. Res. 11, 75 (2014)

8. K. Kotrasova, E. Kormanikova, Key Eng. Mat. 635, 147 (2015)

9. Y. Ohya, H. Hashimoto, S. Ozono, J. Wind. Eng. Ind. Aerod. 67-68, 793 (1997)

10. V. Michalcova, L. Lausova, I. Skotnicova, S. Pospisil, Transactions of the VŠB Technical University of Ostrava, Civil Engineering Series, 16, (2016)

11. V. Michalcova, L. Lausova, I. Skotnicova, S. Kuznetsov, Key. Eng. Mat. (to be published) 